\title{
Morfologia de conídios e patogenicidade de isolados de Exserohilum turcicum da Argentina e do Brasil em milho
}

\author{
Roberto Luis De Rossi ${ }^{1,2}$, Erlei Melo Reis ${ }^{2}$, Ricardo Brustolin ${ }^{2}$
}

${ }^{1}$ Universidad Católica de Córdoba, Córdoba, Argentina; ${ }^{2}$ Universidade de Passo Fundo, Passo Fundo, RS, Brasil.

Autor para correspondência: Roberto Luis De Rossi (robderossi@gmail.com)

Data de chegada: 25/10/2013. Aceito para publicação em: 19/12/2014.

$10.1590 / 0100-5405 / 1948$

\section{RESUMO}

De Rossi, R. L.; Reis, E. M.; Brustolin, R. Morfologia de conídios e patogenicidade de isolados de Exserohilum turcicum da Argentina e do Brasil em milho. Summa Phytopathologica, v.41, n.1, p.58-63, 2015.

A cultura do milho é uma das principais commodities da Argentina e do Brasil. Seu rendimento é reduzido por agentes nocivos, sendo um deles o fungo Exserohilum turcicum (Et) agente causal da helmintosporiose do milho.O presente trabalho teve como objetivo comparar as características morfológicas dos conídios e a patogenicidade de dez isolados de Et obtidos da Argentina e do Brasil. Cinco isolados monospóricos de cada país foram cultivados em meio lactose caseina hidrolizada ágar (LCHA) durante 15 dias a $25^{ \pm} 2^{\circ} \mathrm{C}$ e na ausência de luz. Prepararam-se lâminas microscópicas para a mensuração de 200 conidios de cada isolado. Na média os conídios mediram 10-25 x 30-135 $\mu \mathrm{m}$, apresentando 2-8 septos. Detectaram-se diferenças estatísticas $(p=0,05)$ entre os dez isolados de $E t$ para todas as variáveis medidas (comprimento, largura e número de septos). Apesar da variação, as características mensuradas coincidiram com as registradas na literatura. Na comprovação da patogenicidade, plantas do híbrido de milho Pioneer $\mathrm{P} 1630 \mathrm{H}$, de conhecida suscetibilidade a $E t$, foram inoculadas com a deposição de $0,5 \mathrm{~mL}$ de uma suspensão de conídios de $E t$ na concentração de $5 \times 10^{4}$ conídios $/ \mathrm{mL}$, no cartucho, quando atingiram a quarta folha expandida. Os dez isolados produziram, após os 15 dias da inoculação, uma média de 2,5 lesões/folha; de 39,7 x 3,4 mm de comprimento e largura respetivamente; e $4 \%$ de severidade estimada. Não se observou diferenças significativas na patogenicidade dos dez isolados estudados para nenhum dos critérios patométricos. Houve diferenças morfológicas entre os isolados da Argentina e do Brasil, porém não quanto à patogenicidade. Confirma-se que os isolados utilizados neste trabalho pertencem à espécie Et.

Palavras-chave adicionais: helmintosporiose, Helminthosporium turcicum, Zea mays,

\begin{abstract}
De Rossi, R. L.; Reis, E. M.; Brustolin, R. Conidial morphology and pathogenicity of Exserohilum turcicum isolates of corn from Argentina and Brazil. Summa Phytopathologica, v.41, n.1, p.58-63, 2015.

Corn crop is one of the most important commodities in Argentina and Brazil. Its yield is reduced by different pathogens such as Exserohilum turcicum $(E t)$, the causal agent of Northern leaf blight in corn. This study aimed to compare the morphological characteristics of conidia and the pathogenicity of ten Et isolates obtained from Argentina and Brazil. Five monosporic isolates from each country were cultured on lactose casein hydrolysate agar (LCHA) for 15 days at $25 \pm 2{ }^{\circ} \mathrm{C}$ in the absence of light. Microscopic slides were prepared to measure 200 conidia of each isolate. On average, conidia measured $10-25 \times 30-135 \mu \mathrm{m}$, presenting 2-8 septa. Statistical differences $(p=0.05)$ were detected among the $10 E t$ isolates for all measured variables (length, width and number of septa). Despite such

variation, the recorded characteristics coincided with those reported in the literature. For pathogenicity tests, corn hybrid plants Pioneer P1630H, of known susceptibility to $E t$, were inoculated by the deposition of $0.5 \mathrm{ml}$ of an $E t$ conidial suspension at the concentration of $5 \times 10^{4}$ conidia $/ \mathrm{mL}$, in the whorl, when the fourth leaf was expanded. All ten isolates produced, after the 15 days of inoculation, an average of 2.5 lesions/leaf, of $39.7 \times 3.4 \mathrm{~mm}$ length and width, respectively, and $4 \%$ estimated severity. There were no significant differences in the pathogenicity of all ten studied isolates for any of the pathometric criteria. There were morphological differences between isolates from Argentina and Brazil but not in pathogenicity. This confirms that the isolates used in this study belong to the species $E t$.
\end{abstract}

Additional keywords: Northern corn leaf blight, Helminthosporium turcicum, Zea mays

O milho, Zea mays L., é um dos grãos alimentares mais antigos sendo considerado como uma das três principais culturas de cereais no mundo, juntamente com arroz e o trigo (10).

O Brasil produziu 56,3 milhões de toneladas de milho na safra 2011-2012, e exportou 8,5 milhões de toneladas. AArgentina, na mesma safra, produziu 20,3 milhões de toneladas de milho, e exportou 14,5 milhões de toneladas (11).

Entre as condições adversas que o milho pode enfrentar estão as doenças, entre elas a helmintosporiose do milho, causada por Exserohilum turcicum Leonard \& Suggs (sinom. Helminthosporium turcicum Pass) [teleomorfo Setosphaeria turcica (Lutterell); sinon. Trichometasphaeria turcica Lutterell Leonard \& Suggs)] é uma das principais doenças foliares do milho (13).

Durante epidemias de Exserohilum turcicum (Et), a incidência em plantas pode chegar a $100 \%$, provocando reduções significativas do rendimento $(2,19,20)$. 
Epidemias esporádicas ocorrem mais freqüentemente nas regiões sul e oeste do Brasil, onde causam danos severos no rendimento de grãos (9), de até 50\% (20).

A helmintosporiose do milho é a doença de maior prevalência no centro-norte do estado de Córdoba, na Argentina. A partir de 2007/08, a doença manifestou-se em todas as safras, apresentando severidades que variaram de acordo com as características genéticas dos cultivares. Em híbridos suscetíveis os danos atingiram até $40 \%$, nas safras de 2007/08 e 2009/10 (5).

O milho é intensamente cultivado na Argentina e no Brasil, e muitas empresas produtoras de sementes de milho trabalham em ambos os países. Geralmente existe intercâmbio de material genético, visando obter melhores híbridos comerciais adaptados a cada área produtora. Nas regiões produtoras de milho no Brasil, Gianasi et al. (14) identificaram as raças fisiológicas de $E t ~ 0,2,3, \mathrm{~N}, 1 \mathrm{~N}, 2 \mathrm{~N}, 3 \mathrm{~N}$, $12 \mathrm{~N}, 23 \mathrm{~N}$ e $123 \mathrm{~N}$, utilizando as linhagens diferenciadoras B37 Ht1, B37 Ht2, A619 Ht3, B37 HtN e M64. A informação das raças presentes na Argentina não foi encontrada na literatura consultada, nem com as empresas produtoras de sementes de milho consultadas. Por isso, é importante comparar a morfologia e a patogenicidade de isolados de $E t$, da Argentina e do Brasil. A hipótese testada foi de que há diferenças morfológicas e patogênicas entre os isolados.

O presente trabalho teve como objetivo comparar as características morfológicas dos conídios de 10 isolados de Et (cinco da Argentina e cinco do Brasil) e suas patogenicidades em híbrido de milho suscetível.

\section{MATERIAL E MÉTODOS}

Amostras de folhas de milho, com sintomas da helmintosporiose, oriundas da Argentina e do Brasil, foram analisadas nos anos de 2011 e 2012, no Laboratório de Fitopatologia - Micologia da Universidade de Passo Fundo - RS (UPF).

\section{Identificação e caracterização do agente causal}

Obtenção dos isolados. As amostras foliares foram registradas, herborizadas, identificadas e armazenadas em envelopes, constituindo uma coleção de isolados de $E t$.

O patógeno foi isolado de discos de 9,0 mm de diâmetro, recortados de folhas contendo parte da lesão e do tecido sadio. Realizou-se a assepsia dos materiais pela imersão em álcool $96 \%$ por um minuto, enxague em água destilada e, em seguida, transfencia para uma solução aquosa de hipoclorito de sódio $1 \%$, por três minutos e novamente enxague com água destilada e estéril, por três vezes, para remover o excesso do hipoclorito. Após a desinfestação, foram distribuídos 25 discos, de cada amostra, em caixas de acrílico, tipo gerbox de poliestireno cristal (11 x $11 \times 3,5 \mathrm{~cm}$ de altura), com tampa. No fundo do recipiente foi depositada uma espuma de polietileno $(5 \mathrm{~mm}$ de espessura) e, sobre essa, duas folhas de papel filtro. O material absorvente foi embebido com água destilada e estéril, até a saturação da espuma, constituindo uma câmara úmida. $\mathrm{O}$ material foi levado à câmara de crescimento com temperatura de $25 \pm 2{ }^{\circ} \mathrm{C}$ e fotoperíodo de 12 horas, em prateleiras com três lâmpadas fluorescentes, $40 \mathrm{~W}$ de potência, localizadas a $50 \mathrm{~cm}$ acima dos gerboxes.

A avaliação foi realizada após dois dias de incubação, com um microscópio estereoscópico, identificando a presença de conídios de $E t$ sobre os discos foliares. Da esporulação do fungo no tecido vegetal, retiraram-se conídios, com o auxílio de uma agulha histológica flambada e, transferidos para placas de petri contendo meio de lactose caseína hidrolisada ágar (LCHA), preparado segundo Tuite (24).
Isolamento monospórico. Os isolamentos monospóricos do fungo foram realizados para cinco amostras oriundas da província de Córdoba, Argentina e cinco amostras do estado do Rio Grande do Sul, Brasil, obtidas no ano 2011.

Tabela 1. Identificação de isolados monospóricos de Exserohilum turcicum, de milho

\begin{tabular}{lcc}
\hline País & Cultivar & Denominação \\
\hline Argentina & AW 190 MGRR2 & 01-AR \\
Argentina & DK 670 MG & 02-AR \\
Argentina & DK 747 MGRR2 & 03-AR \\
Argentina & NK 910 TD Max & $04-\mathrm{AR}$ \\
Argentina & P31Y05 H & 05-AR \\
Brasil & AG 9045 convencional & 01-BR \\
Brasil & AG 8011 Pro & $02-\mathrm{BR}$ \\
Brasil & AG 9010 Pro & 03-BR \\
Brasil & DKB 350 Pro & 04-BR \\
Brasil & AG $8025 \mathrm{H}$ & $05-\mathrm{BR}$ \\
\hline
\end{tabular}

Após o desenvolvimento das colônias, adicionou-se $10 \mathrm{~mL}$ de água destilada esterilizada, em cada placa, para a remoção dos conídios. Posteriormente, com o auxílio de um pincel de pelo de camelo número 20, foi feita a remoção dos propágulos. Dessa suspensão, foram pipetados $350 \mu \mathrm{L}$ para cada placa de petri contendo o meio ágar-água (12). Com o auxílio de uma alça de Drigalsky, distribuiu-se a suspensão na superfície do meio de cultura e incubou-se a $25^{ \pm} 2^{\circ} \mathrm{C}$, por $3-6$ horas, com luz contínua.

$\mathrm{Na}$ realização do isolamento monospórico, identificou-se, em microscópio óptico, aumento de $100 \mathrm{x}$, conídios germinados, quando o pró-micélio atingiu o tamanho menor que a metade do diâmetro do conídio. Com o auxílio de uma agulha histológica flambada, cortaramse pequenas porções do meio, contendo apenas um conídio germinado. Cada fragmento foi transferido para uma placa de petri contendo meio de cultura de LCHA. As placas foram incubadas em câmara climatizada, em ambiente controlado, por 15 dias e, após transferiu-se parte da colônia jovem do fungo para tubos de ensaio contendo meio de cultura batata sacarose ágar (BSA) que armazenados na micoteca do laboratório, em refrigerador, a $5^{\circ} \mathbf{C}$.

Caracterização morfológica dos conídios dos isolados. A caracterização morfológica dos conídios foi realizada após a montagem de lâminas individuais dos dez isolados do fungo. Com o auxílio de uma agulha histológica flambada, retiraram-se pequenas porções da colônia, com quinze dias de crescimento em meio LCHA, que foram depositadas sobre uma lâmina contendo uma gota de lactofenol e, cobertos com uma lamínula.

Foram mensurados o comprimento e a largura e contado o número de septos de 50 conídios por lâmina. Utilizou-se para as medidas um retículo micrométrico incorporado à ocular de um microscópio binocular (Olympus CX31), no aumento de 400 x. Cada lâmina constituise numa unidade experimental, para cada isolado foram realizadas quatro repetições.

Análise estatística. Os dados foram submetidos à análise de variância e as médias foram comparadas pelo teste de Scott \& Knott, a $5 \%$ de significância. As análises foram realizadas no software InfoStat 2010 (6). 


\section{Prova de Patogenicidade}

Cultivo das plantas. Plantas de milho foram cultivadas em vasos plásticos contendo $2 \mathrm{~kg}$ de solo utilizando-se sementes do híbrido do milho Pioneer $\mathrm{P} 1630 \mathrm{H}$ (de conhecida susceptibilidade a $E t$ ), híbrido simples, hiperprecoce, com o gene Herculex ${ }^{\circledR}$. Após a emergência, realizou-se o desbaste, permanecendo três plântulas por recipiente. As plantas foram mantidas em casa-de-vegetação com temperatura de 25 ${ }^{ \pm}{ }^{\circ} \mathrm{C}$ e fotoperíodo de 12 horas.

Multiplicação do inóculo. Para se obter a concentração desejada de conídios para a inoculação, procedeu-se a sua multiplicação. Com o auxílio de uma agulha histológica flambada, pequenas porções da colônia, de cada isolado de $E t$, preservada em tubos de ensaio em meio BDA, foram transferidas para placas de petri contendo o meio de cultura LCHA, para estimular sua esporulação. Em seguida, as placas foram vedadas com papel filme de PVC e levadas para uma câmara climatizada, a $25^{ \pm} 2^{\circ} \mathrm{C}$ e escuro, por um período de 15 dias, até obterse esporulação abundante.

Inoculação. A inoculação foi feita com os 10 isolados, quando as plantas atingiram o estádio fenológico V4 (quarta folha expandida, apresentando colar, lígula e aurículas visíveis) (21). Com o auxílio de um micropipetador, ajustado para $0,01 \mathrm{~mL}$, foi feita a contagem de doze gotas em microscópio óptico, ajustando a concentração para $5 \times 10^{4}$ conídios $/ \mathrm{mL}$. Depois da inoculação, foram vertidos $350 \mu \mathrm{d}$ da suspensão em meio ágar-ágar e, após de 3-6 horas, quantificou-se a germinação e obtendo-se a concentração efetiva corrigida.

Para melhorar a cobertura e o molhamento das folhas com a suspensão do inóculo, foi adicionado o tenso ativo poli-oxi-etilenosorbitano monolautaro (Tween 20, Sigma Chemical Co) na proporção de uma gota/L. A inoculação foi realizada por meio da deposição de $0,5 \mathrm{~mL}$ do inóculo no cartucho das plântulas. No tratamento controle (testemunha), a deposição foi feita apenas com água mais o tenso ativo. Foram observadas quatro repetições dos tratamentos. Após a inoculação, as plantas permaneceram em casa-de-vegetação com temperatura de $25^{ \pm} 2^{\circ} \mathbf{C}$ e fotoperíodo de 12 horas, por 14 días.

Fitopatometria. Decorridas duas semanas, quantificou-se o número de lesões/folha e foi realizada a mensuração das lesões, com auxílio de um paquímetro digital (marca Mitutoyo, modelo 500-143B). Consideraram-se apenas as lesões com comprimento maior ou igual a $2 \mathrm{~mm}$. Também foi determinada a severidade da doença, estimada visualmente.

Reisolamento do fungo de lesões em folhas de milho. Para completar o teste de patogenicidade, realizou-se o reisolamento do fungo, das folhas com sintomas da helmintosporiose, em meio LCHA. Previamente, realizou-se a desinfestação dos discos do tecido foliar em solução aquosa de hipoclorito de sódio a $1 \%$, por três minutos, e lavagem com água destilada, retirando o excesso do desinfestante. Em seguida, os discos foram distribuídos em caixas de acrílico, tipo gerbox, preparadas como anteriormente descrito, e mantidos em câmara de crescimento com temperatura de $25^{ \pm} 2{ }^{\circ} \mathrm{C}$ e fotoperíodo de 12 horas. Após dois dias de incubação, com um microscópio estereoscópico, foi identificada a presença de Et. Da esporulação do fungo no tecido vegetal, retiraram-se conídios, com o auxílio de uma agulha histológica flambada e que foram transferidos para placas de petri contendo meio LCHA. Decorridas duas semanas foi realizada a caracterização morfológica dos conídios após a montagem de lâminas individuais dos dez isolados do fungo.

Análise estatística. Os ensaios foram realizados duas vezes utilizando, na análise estatística, as médias dos dados. Os dados foram submetidos à análise de variância e as médias comparadas pelo teste de Tukey, a 5\% de significância. As análises foram realizadas no software InfoStat 2010 (6).

\section{RESULTADOS E DISCUSSÃO}

Identificação e caracterização do agente causal. Quanto às características morfológicas de largura e de comprimento, obtidas por meio das mensurações de duzentos conídios, de cada um dos dez isolados do fungo, os esporos mediram, em média, 10,3-20,3 x 46,5-128,3 $\mu \mathrm{m}$, apresentando 2-8 septos por conídio, sendo os valores mínimos e máximos de largura e comprimento de 10,0-25,0 x 30,0$147,5 \mu \mathrm{m}$, respectivamente.

Tabela 2. Caracterização morfológica de conídios de isolados monospóricos de Exserohilum turcicum obtidos de híbridos de milho coletados na Argentina e no Brasil

\begin{tabular}{|c|c|c|c|c|c|c|c|c|c|}
\hline \multirow[b]{2}{*}{ Isolado } & \multicolumn{3}{|c|}{ Largura $(\mu \mathrm{m}) *$} & \multicolumn{3}{|c|}{ Comprimento $(\mu \mathrm{m})^{*}$} & \multicolumn{3}{|c|}{ Septos $\left(\mathbf{n}^{0}\right)^{*}$} \\
\hline & Mínima & Máxima & Média & Mínimo & Máximo & Médio & Mínimo & Máximo & Médio \\
\hline 01-AR & 10,0 & 22,5 & $14,8 \mathrm{c}^{* *}$ & 47,5 & 125,0 & $95,2 \mathrm{~b}$ & 2 & 8 & $4,6 \mathrm{c}$ \\
\hline 02-AR & 10,0 & 20,0 & $14,4 \mathrm{~d}$ & 40,0 & 125,0 & $92,0 \mathrm{c}$ & 2 & 7 & $4,9 \mathrm{~b}$ \\
\hline 03-AR & 10,0 & 17,5 & $14,2 \mathrm{~d}$ & 30,0 & 115,0 & $85,1 \mathrm{~d}$ & 2 & 7 & $4,9 \mathrm{~b}$ \\
\hline 04-AR & 10,0 & 20,0 & $15,5 \mathrm{~b}$ & 55,0 & 147,5 & $105,0 \mathrm{a}$ & 2 & 7 & $4,9 \mathrm{~b}$ \\
\hline 05-AR & 10,0 & 20,0 & $15,0 \mathrm{c}$ & 62,5 & 135,0 & $105,3 \mathrm{a}$ & 2 & 8 & $4,9 \mathrm{~b}$ \\
\hline 01-BR & 10,0 & 20,0 & $13,8 \mathrm{~d}$ & 37,5 & 125,0 & $91,9 \mathrm{c}$ & 2 & 6 & $4,6 \mathrm{c}$ \\
\hline 02-BR & 12,5 & 20,0 & $15,7 \mathrm{~b}$ & 57,5 & 122,5 & $92,8 \mathrm{c}$ & 3 & 7 & $5,2 \mathrm{a}$ \\
\hline 03-BR & 10,0 & 20,0 & $14,1 \mathrm{~d}$ & 40,0 & 127,5 & $94,8 \mathrm{~b}$ & 2 & 7 & $4,6 \mathrm{c}$ \\
\hline 04-BR & 10,0 & 25,0 & $16,3 \mathrm{a}$ & 52,5 & 132,5 & $96,9 \mathrm{~b}$ & 2 & 8 & $4,4 \mathrm{c}$ \\
\hline 05-BR & 10,0 & 20,0 & $15,7 \mathrm{~b}$ & 42,5 & 127,5 & $98,4 \mathrm{~b}$ & 3 & 7 & $4,8 \mathrm{c}$ \\
\hline Media & 10,3 & 20,3 & 15,0 & 46,5 & 128,3 & 95,7 & 2,2 & 7,2 & 4,8 \\
\hline CV (\%) & & 14,4 & & & 16,1 & & & 20,8 & \\
\hline
\end{tabular}

*Medias de quatro repetições em meio LCHA.

**Medias seguidas pela mesma letra, nas columnas, não diferem pelo teste Scott \& Knott a 5\%. 
Houve diferenças significativas na morfologia dos conídios entre os dez isolados, mas todos próximos das mensurações descritas na literatura.

As dimensões da largura dos conidios, dos 10 isolados, variaram entre 10 e $25 \mu \mathrm{m}$, sendo a média de $15 \mu \mathrm{m}$. A maior largura mínima foi determinada no isolado 02-BR, com $12,5 \mu \mathrm{m}$, os demais isolados apresentaram largura mínima de $10 \mu \mathrm{m}$. A largura máxima foi determinada no isolado 04-BR, com $25 \mu \mathrm{m}$. O isolado 04-BR apresentou a maior largura média de $16,3 \mu \mathrm{m}$, e o isolado 01 -BR apresentou a menor largura média com 13,8 $\mu \mathrm{m}$.

O comprimento dos conidios variou de 30 a 147,5 $\mu \mathrm{m}$, média de $95,7 \mu \mathrm{m}$. O menor comprimento foi determinado no isolado 03-AR com $30 \mu \mathrm{m}$, e o maior no isolado 04-AR, com 147,5 $\mu \mathrm{m}$. No isolado 03-AR determinou-se o menor comprimento médio $(85,1 \mu \mathrm{m})$ e no isolado 05-AR determinou-se o maior, com 105,3 $\mu \mathrm{m}$.

O número de septos variou de 2 a 8 por conídio, sendo que o isolado 04-BR apresentou a menor média $(4,4)$ e o maior foi determinado no isolado 02-BR $(5,2)$.

Os valores obtidos de largura e comprimento ficaram próximas as mensurações descritas por Ellis (8), de 18-32 x 50-144 $\mu$ m, mas variaram quanto ao número de septos, onde Ellis cita entre 4-9 septos. Segundo Shurtleff (22), os conídios apresentam tamanho 20 x $105 \mu \mathrm{m}$ (não especificando os valores mínimos e os máximos) e entre 3 e 8 septos por conídio. Assim, os valores relatados por Shurtleff ficaram ainda mais aproximados aos determinados neste trabalho.

As diferenças observadas podem ser devidas aos diferentes substratos utilizados, idade das colônias e, principalmente, a variabilidade genética.

Knox-Davies \& Dickson (16) relataram evidência da ocorrência de heterocariose, sugerindo que a grande variabilidade na morfologia do fungo $E t$ pode estar relacionada com esta característica.

Ogasawara et al. (18), citaram que os isolados de Helmintosporium spp., geralmente, perdem a capacidade de esporular no meio sintético provavelmente devido as alterações bioquímicas, a nível de aminoácidos, que ocorrem durante a formação de conídio.

Diante disso, há a possibilidade de haver influência do meio utilizado como substrato para depois realizar a caracterização morfológica. Esse cuidado com o substrato para determinações morfológicas não foi explicitado na literatura consultada. O presente trabalho foi conduzido com meio de LCHA, considerando que segundo Tuite (24) é o meio indicado para estimular a esporulação de Et.

Bach \& Kimati (1) realizaram comparações morfológicas dos conídios de dez isolados de Et provenientes de milho, nove deles do Brasil, e um dos Estados Unidos. No trabalho desses autores, foi utilizado o meio BDA para o desenvolvimento dos isolados, tendo-se obtido, na média, 17,67 $\mu \mathrm{m} \times 108,93 \mu \mathrm{m}$ para o comprimento e a largura respectivamente. Bach \& Kimati (1) demostraram que não houve diferenças morfológicas de conídios de isolados de milho em meio de cultura BDA.

Não se encontrou na literatura consultada referências comparando a morfologia e patogenicidade de isolados de $E t$ da Argentina e do Brasil.

Quando são comparadas as características morfológicas dos isolados da Argentina com os do Brasil, houve diferenças significativas entre eles, mas próximos das mensurações descritas na literatura internacional. Os isolados da Argentina apresentaram em média 14,78 $\mu \mathrm{m} \times 96,52 \mu \mathrm{m}$ para o comprimento e a largura respectivamente, e os do Brasil, apresentaram 15,12 $\mu \mathrm{m}$ x 94,96 $\mu \mathrm{m}$.

Patogenicidade. Os resultados positivos das inoculações confirmaram a patogenicidade dos 10 isolados de Et em milho suscetível .

Os esporos dos dez isolados estudados neste trabalho, após de três a cinco horas em meio ágar-ágar, apresentavam germinação superior a $98 \%$, coincidindo em quanto ao tempo necessário com Hilu \& Hooker (15), onde os autores relatam a ocorrência da germinação dos conídios
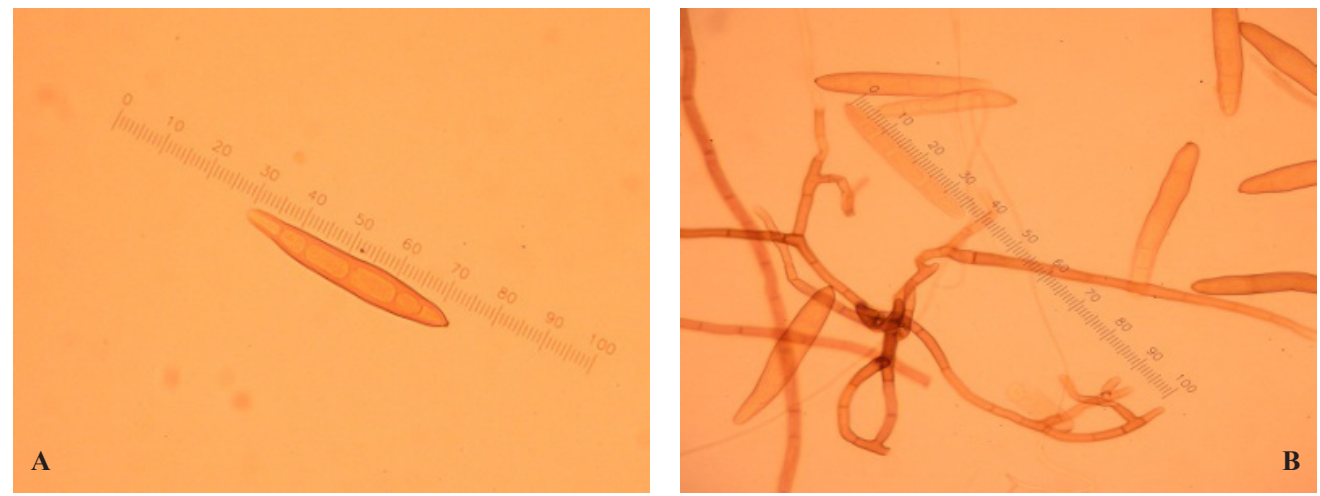

Figura 1. Estruturas de Exserohilum turcicum: a) conídio do isolado 02-BR, b) conídios e conidióforo do isolado 03-AR.

Tabela 3. Características morfológicas de conídios de Exserohilum turcicum segundo diferentes autores

\begin{tabular}{|c|c|c|c|c|}
\hline Autor & Largura $(\mu \mathrm{m})$ & Comprimento $(\mu \mathrm{m})$ & Septos $\left(n^{0}\right)$ & Meio \\
\hline Ellis (1971) & $18-32$ & $50-144$ & $4-9$ & $(-)$ \\
\hline Chidambaram (1973) & $17-22,1$ & $96,9-125,8$ & $4-7$ & $(-)$ \\
\hline Shurtleff (1992) & 20,0 & 105,0 & $3-8$ & $(-)$ \\
\hline Bach \& Kimati (1995) & 17,67 & 108,93 & $(-)$ & $(-)-B D A$ \\
\hline De Rossi \& Reis (2014) & $10-22,5$ & $47,5-110,1$ & $2-8$ & 15-LCHA \\
\hline De Rossi et al.* & $10-25$ & $30-147$ & $2-8$ & 15-LCHA \\
\hline
\end{tabular}

*valores mínimo e máximo (no presente trabalho), **médias (no presente trabalho), (-) sem informação 
Tabela 4. Comparação das características morfológica de conídios de Exserohilum turcicum obtidos da Argentina e do Brasil

\begin{tabular}{cccc}
\hline Pais & Largura $(\boldsymbol{\mu m})$ & Comprimento $(\boldsymbol{\mu m})$ & Septos $\left(\mathbf{n}^{\mathbf{0}}\right)$ \\
\hline Argentina & $14,78 \mathrm{~b}$ & $96,53 \mathrm{a}$ & $4,86 \mathrm{a}$ \\
Brasil & $15,13 \mathrm{a}$ & $94,93 \mathrm{~b}$ & $4,70 \mathrm{~b}$ \\
\hline CV $(\%)$ & 15,3 & 17,2 & 22,1 \\
\hline
\end{tabular}

Medias seguidas por letras distintas diferem pelo teste de Scott \& Knott a 5\%.

de Et entre três e seis horas, e com Stangarlin \& Pascholati (23) que observaram uma germinação, na média de cinco isolados de $E t$, de $97 \%$, mas não explicitaram em que tempo.

Uma semana após a inoculação do patógeno nos cartuchos das plantas do milho do híbrido suscetível $\mathrm{P} 1630 \mathrm{H}$, observaram-se as primeiras lesões foliares de formato elíptico e alongado, de cor verdeacinzentadas, coincidentes com o registrado por Elliot \& Jenkins (7) e por Bach \& Kimati (1).

Segundo Leonard et al. (17), existem dois tipos de resistência para Et no milho: monogênica e poligênica. A primeira (controlada pelo $H t 1, H t 2$ e $H t 3$ ), é caracterizada pela formação de lesões cloróticas e esporulação reduzida ou, quando presente o gene $H t N$, o híbrido que o contém, não evidencia lesões até após a polinização. A resistência poligênica é caracterizada pela menor quantidade de lesões e de menor tamanho.

Duas semanas após a inoculação, no momento da avaliação, não se observaram diferenças significativas na patogenicidade dos dez isolados estudados em nenhum dos parâmetros avaliados: número de lesões/ folha, comprimento $(\mathrm{mm})$, largura $(\mathrm{mm})$ e severidade estimada. Da mesma forma, não foi registrada nenhuma expressão diferenciada entre os isolados, todos apresentando o mesmo formato e tamanho das lesões.

Os dez isolados produziram, aos 15 dias após a inoculação, média de 2,5 lesões/folha. Determinou-se que o isolado 05-AR foi o que apresentou maior número de lesões por folha, com 3,4, e o isolado 03-BR o menor número, 1,7 lesões/folha.

O comprimento médio das lesões foi de $39,7 \mathrm{~mm}$; sendo que o

Tabela 5. Número, comprimento, largura de lesões foliares e severidade estimada dos sintomas causados pela inoculação de dez isolados monospóricos de Exserohilum turcicum em folhas de milho

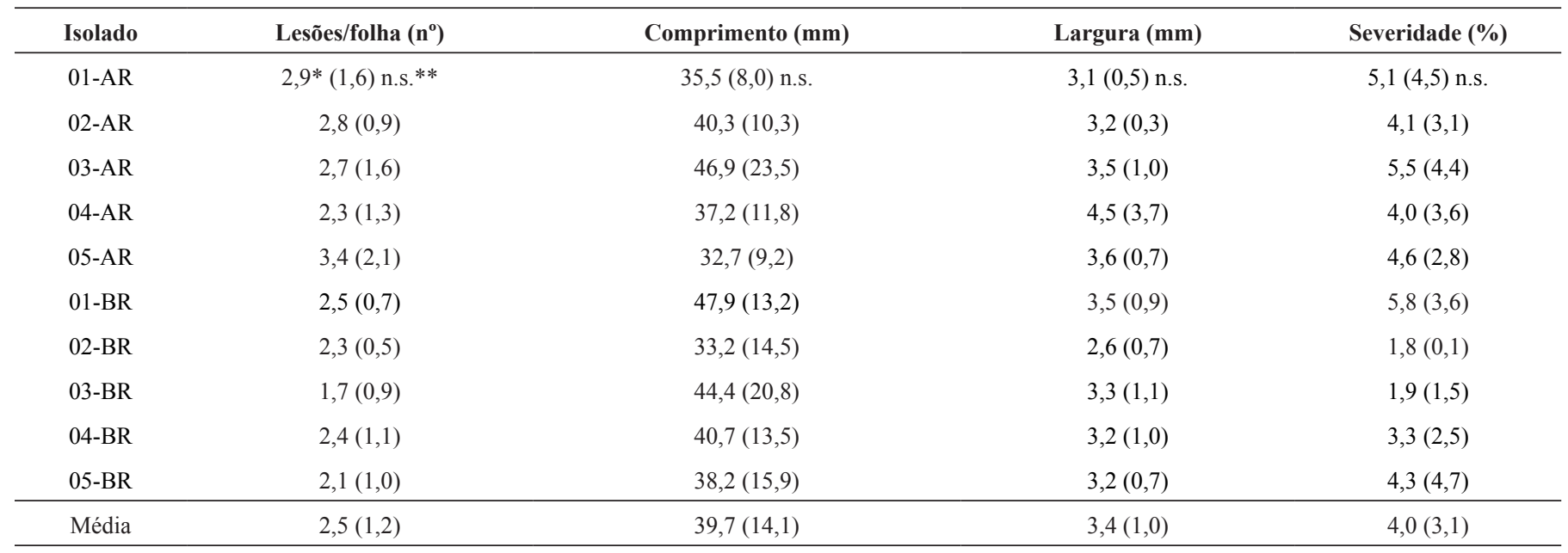

*Medias de quatro repetições, os valores entre parênteses representam o desvio

**n.s. valores não significativos pelo teste Tukey a $5 \%$
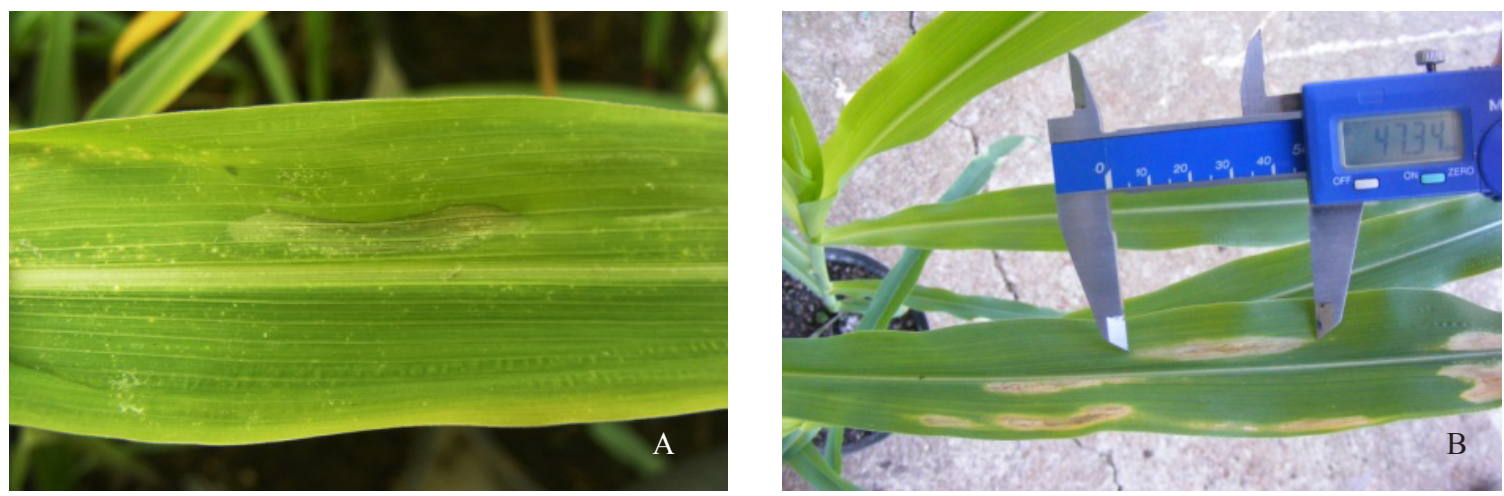

Figura 2. Sintomas de Exserohilum turcicum: a) lesão com uma semana, b) lesão com duas semanas da inoculação. 
isolado 05-AR apresentou o menor comprimento médio com 32,7 mm e o isolado 01-BR, o maior, com 47,9 mm. A largura média das lesões foi de 3,4 mm; a menor largura média, de $2,6 \mathrm{~mm}$, foi produzida pelo isolado $02-\mathrm{BR}$ e o $04-\mathrm{AR}$, a maior, com $4,5 \mathrm{~mm}$.

A severidade estimada média obtida foi de $4 \%$; a menor, com $1,8 \%$, foi causada pelo isolado $02-\mathrm{BR}$ e, a maior, pelo isolado $01-\mathrm{BR}$, com $5,8 \%$.

Não houve diferença estatística entre os isolados, quanto a patogenicidade.

A helmintosporiose do milho tem sido estudada no Brasil e em outros países. No momento esta sendo estudada na Argentina por sua importância ao causar epidemias nas ultimas safras.

Os 10 isolados identificados como Exserohilum turcicum, são valiosos para futuros estudos epidemiológicos, avaliação da reação de linhagens genéticas e variabilidade do agente causal.

Pode-se concluir que houveram diferenças morfológicas entre os isolados da Argentina e do Brasil, porém não quanto à patogenicidade, confirmando que eles estão intimamente relacionados e identificados como Exserohilum turcicum.

\section{REFERÊNCIAS BIBLIOGRÁFICAS}

1. Bach, E.; Kimati, H. Comparação morfologica e patogênica de Exserohilum turcicum, isolado de milho, sorgo e capim massambará. Summa Phytopathologica, Botucatu, v. 21, p. 134-139, 1995.

2. Carson, M. L. Inheritance of latent period length in maize infected with Exserohilum turcicum. Plant Diseases. St. Paul, v. 79, p. 581-585, 1995.

3. Chidambaram, P., Mathur, S.B.; Neergaard, P. Identification of seed-borne Drechslera species. Friesia, Hornbæk, v. 10, p.165-207, 1973.

4. De Rossi, R. L.; Reis, E. M. Semi-selective culture medium for Exserohilum turcicum isolation from corn seeds. Summa Phytopatholica, Botucatu, vol. 40, n. 2, p. 163-167, 2014.

5. De Rossi, R. L.; Guerra, G. D.; Plazas, M. C.; Brücher, E.; Gregoret, M. C. Tizón del maíz (Exserohilum turcicum). Comportamiento sanitario de diferentes híbridos de maíz en la región centro norte de la provincia de Córdoba en la campaña 2009/10. CREA. Buenos Aires, v. 263, p. 70-73, 2011.

6. Di Rienzo, J. A.; Balzarini, M.; Casanoves, F.; Gonzalez, L.; Tablada, M.; Robledo, C. W. InfoStat, software estadístico. Córdoba, Universidad Nacional de Córdoba, Argentina, 2010.

7. Elliot, C. H.; Jenkins, M. T. Helminthosporium turcicum leaf blight of corn. Phytopathology, St. Paul, v. 36, p. 660, 1946.
8. Ellis, M. B. Dematiaceous hyphomycetes. Kew, Surrey: CAB.1971. 608p.

9. Esteves, M. C. F. Reações a Exserohilum turcicum (Pass.) Leonard \& Suggs em milho (Zea mays L.) e variabilidade do patógeno. Tese de mestrado em Escola Superior de Agricultura "Luiz de Queiróz", Universidade de São Paulo, Piracicaba. 1989.

10. FAO. Food and agriculture organization of the United Nations. 2012. DisF ponível em: http://www.faostat.fao.org. Acceso: 18/04/2012.

11. Food and agriculture organization of the United Nations. Global information and early warning system on food and agriculture. Roma, 2012.

12. Fernandez, M. R. Manual para laboratório de fitopatologia. Passo Fundo: EMBRAPA, CNPT. 1933. 128 p. (Documentos, 6).

13. Frederiksen, R. A. Compendium of sorghum diseases. American Phytopathology Society: St. Paul, 1991. 82 p.

14. Gianasi, L.; Castro, H. A.; Silva, H. P. Raças fisiológicas de Exserohilum turcicum identificadas em regiões produtoras de milho no Brasil, safra 93/94. Summa Phytopathologica, Botucatu, v. 22, p. 214-217, 1996.

15. Hilu, H. M., Hooker, A. L. Host-pathogen relationship of Helminsthosporium turcicum in resistant e susceptible corn seedlings. Phytopathology. St. Paul, v. 54, n. 5 , p. $570-575,1964$.

16. Knox-Davies, P. S.; Dickson, J. G. Cytology of Helminthosporium turcicum and its ascigerous stage, Trichometasphaeria turcica. American Journal of Botany, St. Louis, v. 47, n. 5, p. 328-339, 1960.

17. Leonard K. J.; Levy, Y.; Smith, D. R. Proposed nomenclature for pathogenic races of Exserohilum turcicum on corn. Plant Diseases. St. Paul, v. 73, p. 776-777, 1989.

18. Ogasarawa, N.; Honma, N.; Ishiwara, K.; Tanaka, H.; Tamari, K. Biochemical changes during formation of conidia. In: Morphological and biochemical events in plant-parasite interaction, p. 129-139. Ed. Akai, S.; Ouchi, S., Tokyo. Phytopathological Society of Japan, 1971.

19. Ramathani, I.; Biruma, M.; Martin, T.; Dixelius, C.; Okori, P. Disease see verity, incidence and races of Setosphaeria turcica on sorghum in Uganda. European Journal of Plant Pathology, v. 131, p. 383-392, 2011.

20. Raymundo, A. D.; Hooker, A. L. Measurind the relationship between northern corn blight and yield losses. Plant Diseases. St. Paul, v. 65, p. 325-327, 1981

21. Ritchie, S.W.; Hanway, J. J.; Benson, G. O. How a corn plant develops Ames: Iowa State University of Science and Technology, 1993. 26 p. (Special Report, 48).

22. Shurtleff, M. C. Compendium of corn diseases. American Phytopathological Society, St. Paul, 1992. 105 p.

23. Stangarlin, J. R.; Pascholati, S. F. Proteção de plântulas de milho pipoca contra Exserohilum turcicum pelo uso de Saccharomyces cerevisiae. Summa Phytopathologica, Botucatu, v. 20, p. 16-21, 1994.

24. Tuite, J. Plant pathological methods. Fungi and bacteria. Department of botany and plant pathology, Purdue University, 1969. 239p. 